\title{
The use of mineral magnetic measurements as a particulate matter (PM) proxy for road deposited sediments (RDS): Marylebone Road, London
}

\author{
C. A. Booth ${ }^{1}$, C. J. Crosby ${ }^{1}$, D. E. Searle ${ }^{1}$, J. M. Khatib ${ }^{1}$, \\ M. A. Fullen ${ }^{2}$, A. T. Worsley ${ }^{3}$, C. M. Winspear ${ }^{1}$ \\ \& D. A. Luckhurst ${ }^{2}$ \\ ${ }^{1}$ STech, University of Wolverhampton, UK \\ ${ }^{2} S A S$, University of Wolverhampton, $U K$ \\ ${ }^{3} N G A S$, Edge Hill University, UK
}

\begin{abstract}
Road deposited sediments (RDS) are a recognised pollution problem and a worrying public health concern of many urban environments. Linkages between the magneto characteristics of RDS and their particle size properties have been explored to determine the extent to which magnetic technologies can be utilised as a proxy for proffering insights to address pollution challenges. Samples $(\mathrm{n}=$ 60) were collected (May, 2008) along both sides of a busy urban road (Marylebone Road) in central London, UK. Magnetic concentration parameters $(\chi \mathrm{LF}, \chi \mathrm{ARM}$ and SIRM) reveal high levels of magnetic material, when compared to previous urban RDS studies. Correlation analysis between the magnetic parameters and textural parameters $(\chi \mathrm{LF}, \chi \mathrm{ARM}, \mathrm{SIRM}$ and PM1.0, PM2.5, PM10) show significantly strong relationships but, unlike earlier studies, the trends display negative correlations. Despite this kinship not adhering to previously identified trends, this does not mean that mineral magnetic measurements cannot be used as a proxy. Moreover, it simply implies that the nature of any trends needs to be established for specific places before it can be reliably applied as a proxy.
\end{abstract}

Keywords: environmental magnetism, particle size, street dust, built environment, epidemiology, public health. 


\section{Introduction}

Road deposited sediments (RDS) (sometimes referred to as street dust) can be toxic [1-3] and contribute to the particulate matter (e.g. $\mathrm{PM}_{1.0}, \mathrm{PM}_{2.5}, \mathrm{PM}_{10}$ ) loadings of urban sediments. Given the microscopic characteristics of these grains they are easily re-suspended and can become a significant human exposure source. When particles are absorbed through inhalation it can lead to serious health problems, such as cardiovascular disease and respiratory illness [4-6]. In the UK, for instance, it is estimated that 24,000 deaths occur annually due to poor air quality [7].

From an environmental perspective, RDS also cause urban drainage system issues, where urban runoff transfers the mix of sediments and toxic substances to receiving drainage systems and/or watercourses, causing detrimental effects on water quality and the health of the natural environment [8-10]. Other studies have highlighted linkages between road surface runoff and the deleterious influence of inorganic metal toxicants on benthic community structure and function in receiving water bodies $[11,12]$. This is because the composition of RDS comprises a variety of both natural materials (quartz, clay and carbonates) and anthropogenic particles [13, 14]. Typically, anthropogenic sediments are derived from industrial and vehicle-generated sources, causing them to contain both metals (metallic fragments and iron oxides) and organic matter [13, 15].

Previous studies [16-18] have demonstrated the distribution of heavy metals within the built environment, in particular their proximity to roadsides and urban catchments. Heavy metals have been found to be associated with road traffic in urban areas and are known to contain particles associated with vehicle wear (such as tyres, body, brake linings), road surface wear, road paint degradation, vehicle fluids, and particulate emissions [19-22].

There is growing awareness of the issues associated with PM pollution [23], particularly within the built environment arena. As such, programmes of PM monitoring are now commonplace in major towns and cities of many countries. For instance, the UK currently has a network of 64 automatic monitoring sites (using gravimetric analysers of PM concentrations). The suite of sites, forming the 'Automatic Urban and Rural Network' (AURN), operated by the Department for Environment, Food and Rural Affairs (DEFRA), are positioned at strategic urban locations where data is continually measured and monitored (www.airquality.co.uk), recording hourly and daily measurements of $\mathrm{PM}_{10}$, $\mathrm{PM}_{2.5}$, Nitrogen oxides, Sulphur dioxide and Ozone, amongst others.

The European Air Quality Framework Directive (96/62/EC) and the First Air Quality Daughter Directive (1999/30/EC) legislation require $\mathrm{PM}_{10}$ levels not to exceed $50 \mathrm{\mu gm}^{-3}$ for more than 35-days per year and set the maximum annual mean limit at $40 \mathrm{\mu gm}^{-3}$. That said, Marylebone Road is one of the most widely publicised air pollution sites in the UK, where PM concentrations are known to regularly exceed regulatory standards [24-27]. Therefore, this venue was selected so as to validate the potential of adopting an alternative technology for monitoring the PM sizes of RDS. Previous RDS studies, elsewhere, have already shown kinships exist between particle sizes and heavy metal content [28-31] but 
the magnetic signature of RDS has only recently been identified to exhibit significant correlations with these characteristics [32, 33]. However, magnetotechniques have not been widely applied to sites where there are known PM issues and, thus, allow new findings, herein, to be compared with other studies.

This work aims to demonstrate the extent to which particular magnetic concentration parameters can be used as a particle size proxy for urban RDS and attempt to highlight whether any data associations follow the predictable trends of similar studies.

\section{Case study}

Marylebone Road (Fig. 1) is a major arterial route (A501) for traffic (up to seven lanes, including bus lanes) and pedestrians within the city of Westminster (central London) that forms part of the inner London ring-road and marks the northern limit of the London congestion charging zone.

Roadside buildings create an asymmetric street canyon with a height to width ratio of $\sim 0.8$ [34]. The road has consistently high daily mean $\mathrm{PM}_{10}$ levels that regularly exceed legislative requirements (e.g. 185 incidents 2002-2004 [34]; 47

(a)

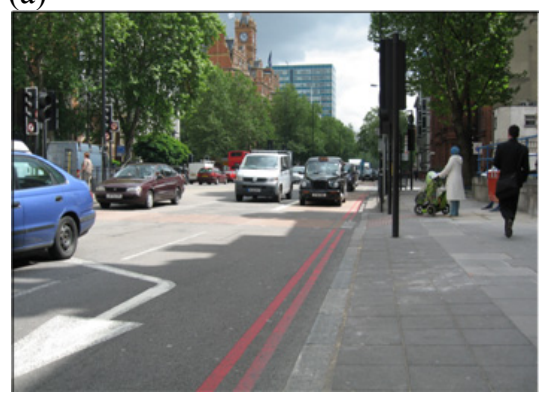

(c)

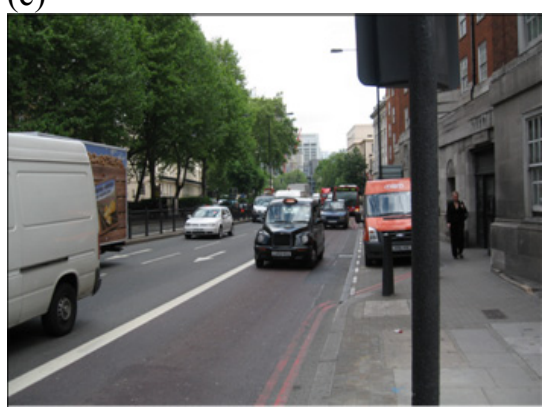

(b)

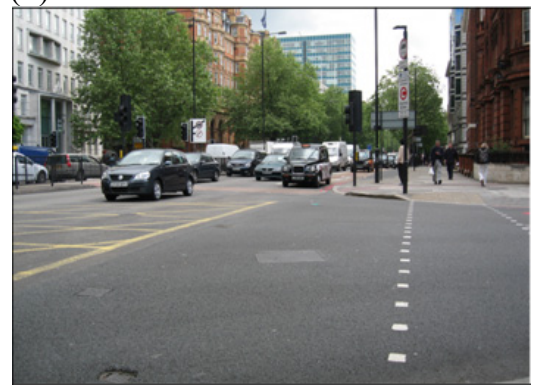

(d)

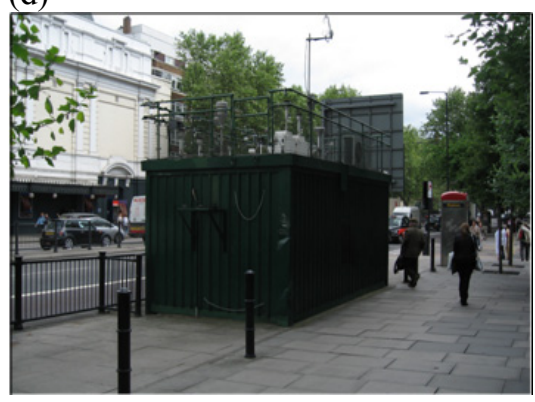

Figure 1: Views of Marylebone Road (May, 2008): (a) Site 9, East facing (Grid reference: 527833 181940); (b) Site 14, East Facing (Grid reference: 527963 181995); (c) Site 29, West facing (Grid reference: 528783 182200); and (d) Site 61, East facing (Grid reference: 526243 180535). 
incidents in 2007; 29 incidents in 2008; and 36 incidents in 2009). These exceedences are thought to be due to congestion and high traffic flows [35], with over 80,000 vehicles per day using the road [34]. This has led to a number of independent studies on PM [25, 34, 36-39], which reveal increases in iron rich dusts [39] and a greater frequency of $\mathrm{PM}_{10}$ exceedences during weekdays when traffic conditions peak [34].

\section{Materials and methods}

\subsection{Sample collection and preparation}

Street dust was collected from the pavements (sidewalks) at regular spacings along both sides of the road. Typically, 10-50 g dust samples were collected (from $\sim 1 \mathrm{~m}^{2}$ ) by brushing with a small hand-held fine-bristle brush. Dust was then transferred to clean, pre-labelled, self-seal, airtight plastic bags. In the laboratory, samples were visibly screened to remove macroscopic traces of hair, animal and plant matter [21].

\subsection{Mineral magnetic measurements}

All samples were subjected to the same preparation and analysis procedure. Samples were dried at room temperature $\left(<40{ }^{\circ} \mathrm{C}\right)$, weighed, packed into $10 \mathrm{ml}$ plastic pots and immobilized with clean sponge foam and tape prior to analysis. Initial, low-field, mass-specific, magnetic susceptibility $(\chi)$ was measured using a Bartington (Oxford, England) MS2 susceptibility meter. By using a MS2B sensor, low frequency susceptibility was measured $\left(\chi_{\mathrm{LF}}\right)$. Anhysteretic Remanence Magnetisation (ARM) was induced with a peak alternating field of $100 \mathrm{mT}$ and small steady biasing field of $0.04 \mathrm{mT}$ using a Molspin (Newcastleupon-Tyne, England) A.F. demagnetiser. The resultant remanence created within the samples was measured using a Molspin 1A magnetometer and the values converted to give the mass specific susceptibility of ARM $\left(\chi_{\text {ARM }}\right)$. The samples were then demagnetized to remove the induced ARM and exposed to a series of successively larger field sizes up to a maximum 'saturation' field of $1000 \mathrm{mT}$, followed by a series of successively larger fields in the opposite direction (backfields), generated by two Molspin pulse magnetisers (0-100 and 0$1000 \mathrm{mT}$ ). After each 'forward' and 'reverse' field, sample isothermal remanent magnetisation (IRM) was measured using the magnetometer [40].

\subsection{Laser diffraction measurements}

All samples were subjected to the same textural preparation and analysis procedure, using sieving (2000 $\mu \mathrm{m}$ aperture) followed by laser diffraction analysis. Low Angle Laser Light Scattering (LALLS), using a Malvern (Malvern, England) Mastersizer Long-bed X with a MSX17 sample presentation unit, enabled rapid measurement of particle sizes within the 0.1-2000 $\mu \mathrm{m}$ range. Macroscopic traces of organic matter were removed from representative sub- 
samples before being dampened by the dropwise addition of a standard chemical solution $\left(40 \mathrm{~g} / \mathrm{l}\right.$ solution of sodium hexametaphosphate $\left(\left(\mathrm{NaPO}_{3}\right)_{6}\right)$ in distilled water) to help disperse aggregates. To ensure complete disaggregation, each slurry was then subjected to ultrasonic dispersion in a Malvern MSX17 sample presentation unit. For greater precision, the mean of five replicate analyses was measured with a mixed refractive indices presentation setting. A standard range of textural parameters was calculated, including the percentage of sand, silt and clay class sizes and their sub-intervals. The Malvern instrumentation was regularly calibrated using latex beads of known size [40].

\section{Results}

Particle size data (Table 1) indicates samples are dominated by sand ( 79\%), silt $(\sim 19 \%)$ and clay $(\sim 2 \%)$, in respective orders. From a respiratory-health perspective, $\mathrm{PM}_{10}$ grains represent $\sim 7 \%, \mathrm{PM}_{2.5} \sim 3 \%$ and $\mathrm{PM}_{1.0} \sim 1 \%$ of the sediments at pavement level. This is noteworthy because, once suspended, particles $<10 \mu \mathrm{m}$ in diameter are able to remain airborne for hours or days and, in some cases, even weeks [41]. Therefore, the presence of PM of these sizes on pavement surfaces indicates either the sediments have not been disturbed recently or they have only just settled-out. Since the pavements normally receive frequent and heavy foot-traffic, it is assumed the time of sampling $(0500-0900)$ and weather conditions (warm, dry and still) have permitted sizeable PM accumulations.

Mineral magnetic characteristics have been summarised (Table 2). $\chi_{\mathrm{LF}}$ is roughly proportional to the concentration of ferrimagnetic minerals within the sample, although in materials with little or no ferrimagnetic component and a relatively large antiferromagnetic component, the latter may dominate the signal. $\chi_{\text {ARM }}$ is particularly sensitive to the concentration of magnetic grains of stable

Table 1: Summary particle size properties of the RDS: (a) traditional sediment size fractions and (b) respiratory health-related size fractions $(n=60$ samples).

\begin{tabular}{|l|c|c|c|c|}
\hline (a) & $\begin{array}{c}\text { Mean } \\
(\mathbf{\%})\end{array}$ & $\begin{array}{c}\text { Minimum } \\
(\mathbf{\%})\end{array}$ & $\begin{array}{c}\text { Maximum } \\
(\mathbf{\%})\end{array}$ & $\begin{array}{c}\text { Standard } \\
\text { Deviation }\end{array}$ \\
\hline Sand $(63-2000 \mu \mathrm{m})$ & 78.88 & 45.92 & 91.45 & 7.98 \\
\hline Silt $(2-63 \mu \mathrm{m})$ & 19.08 & 7.27 & 53.01 & 7.85 \\
\hline Clay $(<2 \mu \mathrm{m})$ & 2.04 & 0.90 & 8.50 & 1.31 \\
\hline
\end{tabular}

\begin{tabular}{|l|c|c|c|c|}
\hline (b) & $\begin{array}{c}\text { Mean } \\
(\mathbf{\%})\end{array}$ & $\begin{array}{c}\text { Minimum } \\
(\mathbf{\%})\end{array}$ & $\begin{array}{c}\text { Maximum } \\
(\mathbf{\%})\end{array}$ & $\begin{array}{c}\text { Standard } \\
\text { Deviation }\end{array}$ \\
\hline$<\mathrm{PM}_{10}$ & 6.57 & 2.84 & 23.99 & 3.88 \\
\hline$<\mathrm{PM}_{2.5}$ & 2.64 & 1.25 & 9.82 & 1.69 \\
\hline$<\mathrm{PM}_{1.0}$ & 1.37 & 0.66 & 5.39 & 1.02 \\
\hline
\end{tabular}


single domain size, e.g. $\sim 0.03-0.06 \mu \mathrm{m}$. SIRM is related to concentrations of all remanence-carrying minerals in the sample, but is also dependent upon the assemblage of mineral types and their magnetic grain size. These data indicate the samples contain moderate to high magnetic concentrations. Compared to previous urban magneto-dust studies, the mean values are sizeably greater than those of Liverpool (23.7 x10-7 $\left.\mathrm{m}^{3} \mathrm{~kg}^{-1}\right)$ [42] and Shanghai $\left(29.9 \times 10-7 \mathrm{~m}^{3}\right.$ $\left.\mathrm{kg}^{-1}\right)$ [43].

Spearman's rank correlation coefficient values $\left(r_{s}\right)$ between the mineral magnetic concentration parameters and particle size parameters have been grouped according to traditional sediment size fractions (Table 3) and respiratory health-related size fractions (Table 4). Significant relationships $(\mathrm{p}<0.001 ; \mathrm{n}=$ $50)$ exist between clay content and all of the magnetic concentration parameters,

Table 2: Summary mineral magnetic properties of the RDS ( $\mathrm{n}=60$ samples).

\begin{tabular}{|l|c|c|c|c|c|}
\hline & Units & Mean & Minimum & Maximum & $\begin{array}{c}\text { Standard } \\
\text { Deviation }\end{array}$ \\
\hline$\chi_{\mathrm{LF}}$ & $10^{-7} \mathrm{~m}^{3} \mathrm{~kg}^{-1}$ & 47.88 & 11.13 & 87.97 & 16.12 \\
\hline$\chi_{\mathrm{ARM}}$ & $10^{-7} \mathrm{~m}^{3} \mathrm{~kg}^{-1}$ & 2.18 & 0.04 & 11.37 & 1.53 \\
\hline SIRM & $10^{-5} \mathrm{Am}^{2} \mathrm{~kg}^{-1}$ & 3779.00 & 956.00 & 6161.00 & 119.80 \\
\hline
\end{tabular}

Table 3: Spearman's rank correlation coefficients (rs) between mineral magnetic concentration and particle size parameters for the RDS based on traditional sediment size fractions.

\begin{tabular}{|l|c|c|c|}
\hline (a) & $\begin{array}{c}\text { Clay } \\
<\mathbf{2} \boldsymbol{\mu m}\end{array}$ & $\begin{array}{c}\text { Silt } \\
\mathbf{2 - 6 3} \boldsymbol{\mu m}\end{array}$ & $\begin{array}{c}\text { Sand } \\
\mathbf{6 3 - 2 0 0 0} \boldsymbol{\mu m}\end{array}$ \\
\hline$\chi_{\text {LF }}$ & $-0.453^{* * *}$ & 0.010 & 0.076 \\
\hline$\chi_{\text {ARM }}$ & $-0.384^{* *}$ & 0.109 & -0.017 \\
\hline SIRM & $-0.386^{* *}$ & -0.049 & 0.135 \\
\hline
\end{tabular}

Note: Significance levels: $\mathrm{p}<0.05=* ; \mathrm{p}<0.01=* * ; \mathrm{p}<0.001=* * *$.

Table 4: Spearman's rank correlation coefficients (rs) between mineral magnetic concentration and particle size parameters for the RDS based on respiratory health-related size fractions $(n=60$ samples $)$.

\begin{tabular}{|l|c|c|c|}
\hline (b) & $<\mathbf{P M}_{1.0}$ & $<\mathbf{P M}_{2.5}$ & $<\mathbf{P M}_{10}$ \\
\hline$\chi_{\text {LF }}$ & $-0.589 * * *$ & $-0.575 * *$ & $-0.526 * *$ \\
\hline$\chi_{\text {ARM }}$ & $-0.511 * *$ & $-0.471 * *$ & $-0.402 * *$ \\
\hline SIRM & $-0.554 * *$ & $-0.553 * *$ & $-0.519 * *$ \\
\hline
\end{tabular}

Note: Significance levels: $\mathrm{p}<0.05=* ; \mathrm{p}<0.01=* * ; \mathrm{p}<0.001=* * *$. 
which is similar for each of the $\mathrm{PM}_{10}, \mathrm{PM}_{2.5}$ and $\mathrm{PM}_{1.0}$ sizes. Therefore, this indicates all the magnetic concentration parameters could potentially be used as a particle size proxy, particularly if the kinship is required with particles $<\mathrm{PM}_{10}$.

\section{Discussion}

Earlier sedimentological works have noted significant correlations exist between magnetic and particle size properties. Oldfield et al. [44] identified anhysteretic remanent magnetisation (ARM) measurements reflect the concentration of finegrained magnetite $(<0.1 \mu \mathrm{m})$ in clay fractions and $\chi_{\mathrm{LF}}$ measurements can be used to infer the presence of coarser multi-domain magnetite $(>1.0 \mu \mathrm{m})$ in sands and coarse silts. Clifton et al. [45] found $\chi_{\mathrm{LF}}$ was strongly associated with sands and medium silts, $\chi_{\text {ARM }}$ was strongly associated with clay and fine silts, and SIRM was strongly associated with very fine to medium silts. Zhang et al. [46] suggested that both percentage frequency-dependent magnetic susceptibility $\left(\chi_{\mathrm{FD} \%}\right)$ and $\chi_{\mathrm{ARM}}$ can be used as a proxy for clay content.

These studies have illustrated sand to correlate negatively with $\chi_{\mathrm{LF}}(\mathrm{r}=$ $-0.94), \chi_{\text {ARM }}(r=-0.96)$ and SIRM $(r=-0.91)$; silt to correlate positively with $\chi_{\text {LF }}$ $(\mathrm{r}=0.96), \chi_{\mathrm{ARM}}(\mathrm{r}=0.96)$ and SIRM $(\mathrm{r}=0.96)$; and clay to correlate positively with $\chi_{\mathrm{LF}}(\mathrm{r}=0.82), \chi_{\mathrm{ARM}}(\mathrm{r}=0.94)$ and SIRM $(\mathrm{r}=0.81)$. When data presented here are compared to earlier investigations, it is apparent that each magnetic parameter also correlates with particle size but the significance is only notable with clay fraction and not the sand and silt fractions. Nevertheless, on first observation, this highlights the potential use of mineral magnetic data as a means of normalizing compositional analytical data (i.e. geochemical) for particle size. However, an important disparity is that the trends observed in this work show negative relationships with the clay fraction, while previous works have always revealed positive trends with the clay fraction. This highlights a sizeable issue for the universal application of mineral magnetic measurements as a particle size proxy.

Previous RDS works have also noted significant correlations exist between $\chi_{\mathrm{LF}}, \chi_{\mathrm{ARM}}, \mathrm{SIRM}$ and respiratory health-related particle size fractions. Booth $e t$ al. [32] revealed $\mathrm{PM}_{10}$ to correlate with $\chi_{\mathrm{LF}}(\mathrm{r}=0.69 ; \mathrm{p}<0.001 ; \mathrm{n}=50) ; \mathrm{PM}_{2.5}$ to correlate with $\chi_{\mathrm{LF}}(\mathrm{r}=0.71 ; \mathrm{p}<0.001 ; \mathrm{n}=50), \chi_{\mathrm{ARM}}(\mathrm{r}=0.30 ; \mathrm{p}<0.05 ; \mathrm{n}=50)$ and SIRM $(\mathrm{r}=0.33 ; \mathrm{p}<0.05 ; \mathrm{n}=50)$; and $\mathrm{PM}_{1.0}$ to correlate with $\chi_{\mathrm{LF}}(\mathrm{r}=0.66 ; \mathrm{p}$ $<0.001 ; \mathrm{n}=50), \chi_{\text {ARM }}(\mathrm{r}=0.41 ; \mathrm{p}<0.01 ; \mathrm{n}=50)$ and SIRM $(\mathrm{r}=0.32 ; \mathrm{p}<0.05 ; \mathrm{n}$ $=50)$. Similarly, Crosby et al. [33] revealed $\mathrm{PM}_{10}$ to correlate with $\chi_{\mathrm{ARM}}(\mathrm{r}=$ $0.44 ; \mathrm{p}<0.01 ; \mathrm{n}=35)$ and SIRM $(\mathrm{r}=0.43 ; \mathrm{p}<0.01 ; \mathrm{n}=35) ; \mathrm{PM}_{2.5}$ to correlate with $\chi_{\text {ARM }}(\mathrm{r}=0.45 ; \mathrm{p}<0.01 ; \mathrm{n}=35)$ and SIRM $(\mathrm{r}=0.43 ; \mathrm{p}<0.01 ; \mathrm{n}=35)$; and $\mathrm{PM}_{1.0}$ to correlate with $\chi_{\mathrm{ARM}}(\mathrm{r}=0.42 ; \mathrm{p}<0.01 ; \mathrm{n}=35)$ and SIRM $(\mathrm{r}=0.40 ; \mathrm{p}$ $<0.05 ; \mathrm{n}=35$ ).

Marylebone Road displays similar correlation significance levels to those of the towns of both Southport [32] and Scunthorpe [33]. However, a notable discrepancy in the correlations is that Marylebone Road again displays significant negative trends; whereas, both of the other places have significant 
positive trends. As such, this represents a potential flaw in the use of mineral magnetic measurements as a universal proxy. However, despite this apparent setback, it does not mean that mineral magnetic measurements cannot be used as a proxy. Moreover, it simply implies that the nature of any trends needs to be established for specific places before it can be reliably applied as a proxy.

These differences offer an opportunity to provide speculative reasoning to explain the outcomes; whereby, it is postulated that the differences are due to the RDS being derived from different sources that have varying characteristics and/or are derived from several mixed sources. To support this argument, attention is drawn to the similarities and disparity of the venues already mentioned. For instance, given the size and restrictive (street canyon) nature of Marylebone Road it is proposed that the RDS are chiefly derived from a singular source (i.e. vehicular); whereas, Southport is a seaside resort with no noteworthy industry so it is proposed that the RDS are probably derived from more than one main source (i.e. a mix of wind-blown coastal sediments and vehicular derived dusts); likewise, Scunthorpe is celebrated as an iron and steel town so it is proposed that the RDS are also probably derived from more than one main source (i.e. a mix of industrial emissions and vehicular derived dusts). Verification of this reasoning would require detailed investigation, such as SEM analyses and/or complex sediment source modelling. However, as with most investigations, these findings promote the need for further research on the reliability of using magnetic technologies as a pollution proxy but, likewise, it also offers a provoking avenue to expand the work to provenance studies.

\section{Future work}

This work forms part of a wider investigation that includes other places in the UK (Dumfries, Norwich, Oswestry, Runcorn, Salford, Scunthorpe and Wolverhampton), which is attempting to address the same aims as those posed in this particular work. It is anticipated that it will offer better insights into the reliability of using mineral magnetic measurements as a particulate matter proxy.

\section{Conclusions}

As with previous studies, this work indicates each of the magnetic concentration parameters could be reliably employed as a particle size proxy for urban RDS, where the finest fraction $(<10 \mu \mathrm{m})$ is the focus. However, the trends displayed in this work are negative correlations and, since this is unlike other studies, it indicates that the perceived universal relationship does not always exist like previously proposed. Despite this potential discrepancy in its suitability, it does not mean that mineral magnetic measurements cannot be used as a proxy. Moreover, it simply implies that the nature of any trends needs to be established for specific places before it can be reliably applied as a proxy. 


\section{Acknowledgements}

This research forms part of a doctoral investigation supported by the School of Technology at the University of Wolverhampton, for which the second author expresses his gratitude. All authors also thank the School of Applied Sciences at the University of Wolverhampton for unlimited access to analytical facilities. Thanks are also extended to Charlotte Turner for her assistance in preparation of this research article.

\section{References}

[1] Zhang, M. \& Wang, H. (2009) Concentrations and chemical forms of potentially toxic metals in road-deposited sediments from different zones of Hangzhou, China. Journal of Environmental Sciences, 21, 625-631.

[2] Shi, G., Chen, Z., Bi, C., Li, Y., Teng, J., Wang, L. \& Xu, S. (2010) Comprehensive assessment of toxic metals in urban and suburban street deposited sediments (SDSs) in the biggest metropolitan area of China. Environmental Pollution, 158, 694-703.

[3] Faiz, Y., Tufail, M., Tayyeb Javed, M., Chaudhry, M.M. \& Siddique, N. (2009) Road dust pollution of $\mathrm{Cd}, \mathrm{Cu}, \mathrm{Ni}, \mathrm{Pb}$ and $\mathrm{Zn}$ along Islamabad Expressway, Pakistan. Microchemical Journal, 92, 186-192.

[4] Brunekreef, B. \& Holgate, S.T. (2002) Air pollution and health. The Lancet, 360, 1233-1242.

[5] Englert, N. (2004) Fine particulates and human health - a review of epidemiological studies. Toxicology Letters, 149, 235-242.

[6] Gulland, A. (2002) Air pollution responsible for 600,000 premature deaths worldwide. British medical Journal, 325, 1380-1381.

[7] Department of Health (1998) Quantification of health effects of air pollution in the United Kingdom committee on the medical effects of air pollution. London: The Stationary Office.

[8] Pontier, H., Williams, J.B. \& May, E. (2004) Progressive changes in water and sediment quality in a wetland system for control of highway runoff. Science of the Total Environment, 319, 215-224.

[9] Zanders, J.M. (2005) Road sediment: characterization and implications for the performance of vegetated strips for treating road run-off. Science of the Total Environment, 339, 41-47.

[10] Sutherland, R.A., Pearson, D.G. \& Ottley, C.J. (2007) Platinum-group elements (Ir, Pd, Pt and $\mathrm{Rh}$ ) in road deposited sediments in two urban watersheds, Hawaii. Applied Geochemistry, 22, 1485-1501.

[11] Maltby, L., Boxall, A.B.A., Forrow, D.M., Calow, P. \& Betton, C.I. (1995) The effects of motorway runoff on freshwater ecosystems: 2 Identifying major toxicants. Environmental Toxicology and Chemistry, 14, 1093-1101.

[12] Pitt, R., Field, R., Lalor, M. and Brown, M. (1995) Urban stormwater toxic pollutants: assessment, sources, and treatability. Water Environment Research 67, 260-275. 
[13] Perry, C. \& Taylor, K. (2007) Environmental Sedimentology. Blackwell Publishing, Oxford.

[14] Taylor, K.G. \& Robertson, D.J. (2009) Electron microbeam analysis of urban road-deposited sediment, Manchester, UK: Improved source discrimination and metal speciation assessment. Applied Geochemistry, 24, 1261-1269.

[15] Fergusson, J.E. \& Ryan, D.E. (1984) The elemental composition of street dust from large and small urban areas related to city type, source and particle size. Science of the Total Environment, 34, 101-116.

[16] Herngren, L., Goonetilleke, A. \& Ayoko, G.A. (2006) Analysis of heavy metals in road deposited sediments. Analytica Chimica Acta, 571, 270-278.

[17] Rijkenberg, M.J.A. \& Depree, C.V. (2010) Heavy metal stabilization in contaminated road-derived sediments. Science of the Total Environment, 408, 1212-1220.

[18] Duong, T.T. \& Lee, B.K. (2011) Determining contamination level of heavy metals in road dust from busy traffic areas with different characteristics. Journal of Environmental Management, 92, 554-562.

[19] De Miguel, E., Llamas, J., Chacon, E., Berg, T., Larssen, S., Royset, O. \& Vadset, M. (1997) Origin and patterns of distribution of trace elements in street dust: unleaded petrol and urban lead. Atmospheric Environment, 31, 2733-2740.

[20] Sutherland, R.A \& Tolosa, C.A. (2000) Multi-element analysis of road deposited sediment in an urban drainage basin, Honolulu, Hawaii. Environmental Pollution, 110, 483-495.

[21] Shilton, V.F., Booth, C.A., Giess, P., Mitchell, D.J. \& Williams, C.D. (2005) Magnetic properties of urban street dust and its relationship to organic matter content in the West Midlands, U.K. Atmospheric Environment, 39, 3651-3659.

[22] Manno, E., Varrica, D. \& Dongarra, G. (2006) Metal distribution in road dust samples collected in an urban area close to a petrochemical plant at Gela, Sicily. Atmospheric Environment, 40, 5929-5941.

[23] Amato, F., Pandolfi, M., Viana, M., Querol, X., Alastuey, A. \& Moreno, T. (2009) Spatial and chemical patterns of $\mathrm{PM}_{10}$ in road dust deposited in urban environment. Atmospheric Environment, 43, 1650-1659.

[24] Scaperdas, A. \& Colvile, R.N. (1999) Assessing the representativeness of monitoring data from an urban intersection site in central London, UK. Atmospheric Environment, 33, 661-674.

[25] Kaur, S., Nieuwenhuijsen, M.J., Colvile, R.N., (2005) Pedestrian exposure to air pollution along a major road in Central London, UK. Atmospheric Environment, 39, 7307-7320.

[26] Bigi, A. \& Harrison, R.M. (2010) Analysis of the air pollution climate at a central urban background site. Atmospheric Environment, 44, 2004-2012.

[27] Wang, H., Colvile, R.N., Pain, C., Aristodemou, E. \& ApSimon, H.M. (2011) Understanding peak pedestrian exposures due to traffic emissions within the urban environment. Transportation Research Part D: Transport and Environment, 16, 392-401. 
[28] Sutherland, R.A. (2003) Lead in grain size fractions of road deposited sediment. Environmental Pollution, 121, 229-237.

[29] Adachi, K \& Tainosho, Y. (2005) Single particle characterization of sizefractionated road sediments. Applied Geochemistry, 20, 849-859.

[30] Zhao, H., Li, X., Wang, X. \& Tian, D. (2010) Grain size distribution of road deposited sediment and its contribution to heavy metal pollution in urban runoff in Beijing, China. Journal of Hazardous Materials, 183, 203210.

[31] Fujiwara, F., Rebagliati, R.J., Dawidowski, L., Gómez, D., Polla, G., Pereyra, V. \& Smichowski, P. (2011) Spatial and chemical patterns of size fractionated road dust collected in a megacity. Atmospheric Environment, 45, 1497-1505.

[32] Booth, C.A., Winspear, C.M., Fullen, M.A., Worsley, A.T., Power, A.L. \& Holden, V.J.C. (2007) A pilot investigation into the potential of mineral magnetic measurements as a proxy for urban roadside particulate pollution. In: Air Pollution XV (Editors) C.A. Borrego \& C.A Brebbia, WIT Press, 391-400.

[33] Crosby, C.J., Booth, C.A., Worsley, A.T., Fullen, M.A., Searle, D.E., Khatib, J.M. \& Winspear, C.M. (2009) Application of mineral magnetic concentration measurements as a particle size proxy for urban road deposited sediment. In: Brebbia, C.A. \& Popov, V. (Eds), Air Pollution XVII, WIT Press, Southampton, 153-162.

[34] Charron, A., Harrison, R.M. \& Quincey, P. (2007) What are the sources and conditions responsible for exceedences of the $24 \mathrm{~h} \mathrm{PM}_{10}$ limit value $\left(50 \mu \mathrm{g} \mathrm{m}^{-3}\right)$ at a heavily trafficked London site? Atmospheric Environment, 41, 1960-1975.

[35] Air Quality Expert Group (2005) Particulate Matter in the United Kingdom: Summary. DEFRA, London.

[36] Thorpe, A.J., Harrison, R.M., Boulter, P.G. \& Mccrae, I.S. (2007) Estimation of particle resuspension source strength on a major London Road. Atmospheric Environment, 41, 8007-8020.

[37] Chen, T., Gokhale, J., Shofer, S. \& Kuschner, W. (2007) Outdoor Air Pollution: Particulate Matter Health Effects. The American Journal of the Medical sciences, 333, 235 - 243.

[38] Fuller, G.W. \& Green, D. (2006) Evidence for increasing concentrations of primary $\mathrm{PM}_{10}$ in London. Atmospheric Environment, 40, 6134-6145.

[39] Harrison, R.M., Jones, A.M. \& Lawrence, R.G. (2004) Major component composition of $\mathrm{PM}_{10}$ and $\mathrm{PM}_{2.5}$ from roadside and urban background sites. Atmospheric Environment, 38, 4531-4538.

[40] Booth, C.A., Walden, J., Neal, A. \& Smith, J.P. (2005) Use of mineral magnetic concentration data as a particle size proxy: a case study using marine, estuarine and fluvial sediments in the Carmarthen Bay area, South Wales, U.K. Science of the Total Environment, 347, 241-253.

[41] Harrison, R.M. (2004) Key pollutants - airborne particles. Science of the Total Environment, 334, 3-8. 
[42] Xie, S., Dearing, J.A. \& Bloemandal, J. (2000) The organic matter content of street dust in Liverpool, UK and its association with dust magnetic properties. Atmospheric Environment, 34, 269-275.

[43] Shu, J., Dearing, J.A., Morse, A.P., Yu, L. \& Yuan, N. (2001) Determining the source of atmospheric particles in Shanghai, China, from magnetic geochemical properties. Atmospheric Environment, 35, 2615-2625.

[44] Oldfield, F., Richardson, N., Appleby, P.G. \& Yu, L. (1993) ${ }^{241}$ Am and ${ }^{137} \mathrm{Cs}$ activity in fine grained saltmarsh sediments from parts of the N.E. Irish Sea shoreline. Journal of Environmental Radioactivity, 19, 1-24.

[45] Clifton, J., McDonald, P., Plater, A. \& Oldfield, F. (1999) Derivation of a grain-size proxy to aid the modelling and prediction of radionuclide activity in saltmarshes and mud flats of the Eastern Irish Sea. Estuarine, Coastal and Shelf Science, 48, 511-518.

[46] Zhang, W., Yu, L. \& Hutchinson, S.M. (2001) Diagenesis of magnetic minerals in the intertidal sediments of the Yangtze Estuary, China, and its environmental significance. Science of the Total Environment, 266, $160-175$. 